INTERDISCIPLINARIA ARCHAEOLOGICA NATURAL SCIENCES IN ARCHAEOLOGY

News and views

\title{
Archaeobotanical Database of the Czech Republic, an Interim Report
}

\author{
Adéla Pokornáa ${ }^{*}$, Dagmar Dreslerováa, Dana Křivánkováa \\ anstitute of Archaeology of the Academy of Sciences of the Czech Republic, v.vi., Letenská 4, 118 01, Praha 1, Czech Republic
}

\section{ARTICLE INFO:}

\section{Article history:}

Received: 30 April 2011

Accepted: 22 August 2011

\section{Keywords:}

archaeobotany

archaeological periods

botanical macroremains

Czech Republic

database program ArboDat

\begin{abstract}
$A B S T R A C T$ :
Archaeobotanical research in the Czech Republic has generated enormous quantities of unique, but non-uniform, data that are currently stored in disparate hard copy and electronic formats. A consortium of archaeological organisations has initiated the Archaeobotanical Database of the Czech Republic $(C Z A D)$ to facilitate data storage, access and quality. $C Z A D$ is being developed under the auspices of the ArboDat Project, by the Institute of Archaeology, Prague, and Landesamt für Denkmalpflege, Hessen, Ger. CZAD is based on the international ArboDat Multi version of the ArboDat database originally developed in Germany. Adaptations have been made to suit local requirements. As at the end of 2010 more than half of the existing data in the Czech Republic has been entered into CZAD. Data entry is on a strictly voluntary basis and author's data and copyright are protected.
\end{abstract}

\section{Introduction}

The analysis of plant macro-remains is a useful tool for obtaining archaeobotanical data that can help solve many issues, including such diverse questions as: past subsistence strategies; crop husbandry regimes; human diet; vegetation and climate changes; or effects of human activities on the landscape. It can further our understanding of the use of wild plants for medicinal and technical purposes and help us, for example, to reconstruct long distance trade in exotic crops. Today, archaeobotany's position as a respected branch of science has arisen both from a gradual awareness of the high information content of biological data from archaeological investigations, and an increasing interest in the everyday life of past humans and their relationship with the local environment.

The increasing number of macro-remains analyses in recent decades has led to the urgent need for a uniform treatment of data in an electronic form. To this end the new Archaeobotanical Database for the Czech Republic (CZAD)

"Corresponding author. E-mail: pokorna@arup.cas.cz was developed at the Institute of Archaeology, Prague. In this article we outline the factors that lead to the creation of the database, of its philosophy and technical execution, and the current state of its development.

\section{Computing archaeobotanical data}

The idea to design a new database for the rapidly accumulating archaeobotanical data arose several years ago. Researchers from the Laboratory of Archaeobotany and Palaeoecology (LAPE); the West Bohemian Institute for Protection and Documentation of Monuments (ZIP); and the Institute of Archaeology in Prague (ARUP) agreed to use a unified database that allowed for the efficient exchange, processing and utilization of data. The database would also make possible the centralization and archiving of all archaeobotanical data in the Czech Republic. However, the creation of a new database system might lead to complications in subsequent steps in data synthesis, such as the interpretation of archaeobotanical data from Czech localities within a larger European context.

The decision was therefore taken to use an existing database program ArboDat developed by A. Kreuz and 
E. Schäfer of the Landesamt für Denkmalpflege Hessen in Wiesbaden, Germany. This program has very sophisticated utilities for archiving and evaluating archaeobotanical data (Kreuz, Schäfer 2002). It was created using MS:Access, designed and adapted for handling archaeobotanical data, with specific adaptations allowing supra-regional and international collaboration on questions that go beyond the borders of individual states. In addition to its archival function, the program incorporates tools for data evaluation and further processing. The hierarchical organization of ArboDat enables easy access not only for archaeobotanical data, but also for background archaeological and ecological information concerning sites, archaeological features, archaeobotanical samples and the ecological characteristics of plant species. ArboDat is already being used by a range of archaeobotanists, including many in Germany, Austria, Switzerland, Denmark, the Netherlands, Belgium, France, Poland and Finland.

In 2009, ARUP established a cooperation with Landesamt für Denkmalpflege Hessen in Wiesbaden (represented by Prof. Angela Kreuz). The bilateral ArboDat project, supported by the Academy of Science of the Czech Republic (ASCR) was launched for the purpose of:

1) translating the original German version of the program into English to enable more widespread use of the software in non-German-speaking countries. This was developed later into a multilingual version of ArboDat, called ArboDat Multi (software solution D. Křivánková), which is based on a universal program code. The universal code enables the use of ArboDat Multi in various language versions and still allows universal upgrades of the program independent of the language. Any new language version of the database can be made by simply translating and filling in all the necessary terms into the translation tables that are an inseparable part of the database. In cooperation with A. Kreuz and the team of S. Thiebault (Department Archéozoologie-Archéobotanique, CNRS, Paris, France), three language versions of ArboDat Multi have so far been prepared (Czech, French and English) in addition to the original German. The local or "country" versions of the ArboDat cater to the specific needs of each country (e.g. the listing of archaeological cultures or phyto-geographical areas). Three local versions now exist for Germany, France and the Czech Republic.

2) establishing and preparing CZAD using ArboDat allow: (a) the collection of data (results of archaeobotanical analyses both published and unpublished); (b) online access for the professional community to basic information in CZAD; (c) a facility to exchange and share data between archaeobotanists, both in the Czech Republic and abroad; and (d) an overview of all archaeobotanical data that will help in identifying preferences for further investigation.There is general agreement that $C Z A D$ data will be stored at ARUP. This arrangement will allow interconnection between $C Z A D$ and the Czech Archaeological Database which would substantially improve the objective of combining both archaeological and archaeobotanical data. ARUP guarantees protection of authors' copyright and data. The provision of data to $C Z A D$ will be on a voluntary basis.

\section{ArboDat program}

ArboDat and its adaptations enable the insertion and further processing of results from macro-remains analyses (including wood and charcoal). The uniform coding of plant taxa is fundamental to the subsequent exchange of the data. A system created by S. Jacomet in Basel (Paulsen 1995) has been used as the basis for the plant coding (PCODE). The results section of ArboDat contains, among other things, the $P C O D E$ of each identified macro-remain, the type of macroremain (i.e. seed/fruit, rachis, root, wood, etc.), the state of its preservation (i.e. charred, desiccated, etc.) and the number of macro-remains of the taxon (this counting is subject to detailed rules listed in the manual of the program).

Information concerning the archaeological site and the context of analysed samples are structured hierarchically (see Form view in Figure 1). Some selected data are entered through pull-down menus, in particular data essential for further evaluation of results (archaeological dating, feature type, site type, type of sampling, type of macro-remain, preservation of macro-remain, etc.) The structure of the database also includes ecological information concerning the plant taxa involved (for more detailed information see Kreuz, Schäfer 2002). ArboDat also contains a dozen preprogrammed queries designed for the evaluation of data according to the choice and requirements of the user.

As the ArboDat was originally designed for use in Germanspeaking countries, all the forms, tables and structural data were obviously written in the German language. Moreover, the whole database system had been designed according to the requirements of German users. Therefore, some changes in the structural data (e.g. the list of archaeological cultural groups or phyto-geographical units) had to be made and the appearance of some forms adapted, for the program to be used in our country. These changes were incorporated into the structure of the multilingual version (ArboDat Multi, see above).

\section{4. $C Z A D$ database}

Archaeobotanical identification of plant macro remains from prehistoric and medieval archaeological contexts has an eighty years tradition in the Czech Republic (Čulíková 2004; Dreslerová 2008; Kočár, Dreslerová 2010). The vast amount of archaeobotanical data from nearly 300 prehistoric and several hundred medieval sites has led us to create a centralized database to incorporate all archaeobotanical data from our country. $C Z A D$ is open to all data from archaeological and off-site contexts. Moreover, the database 


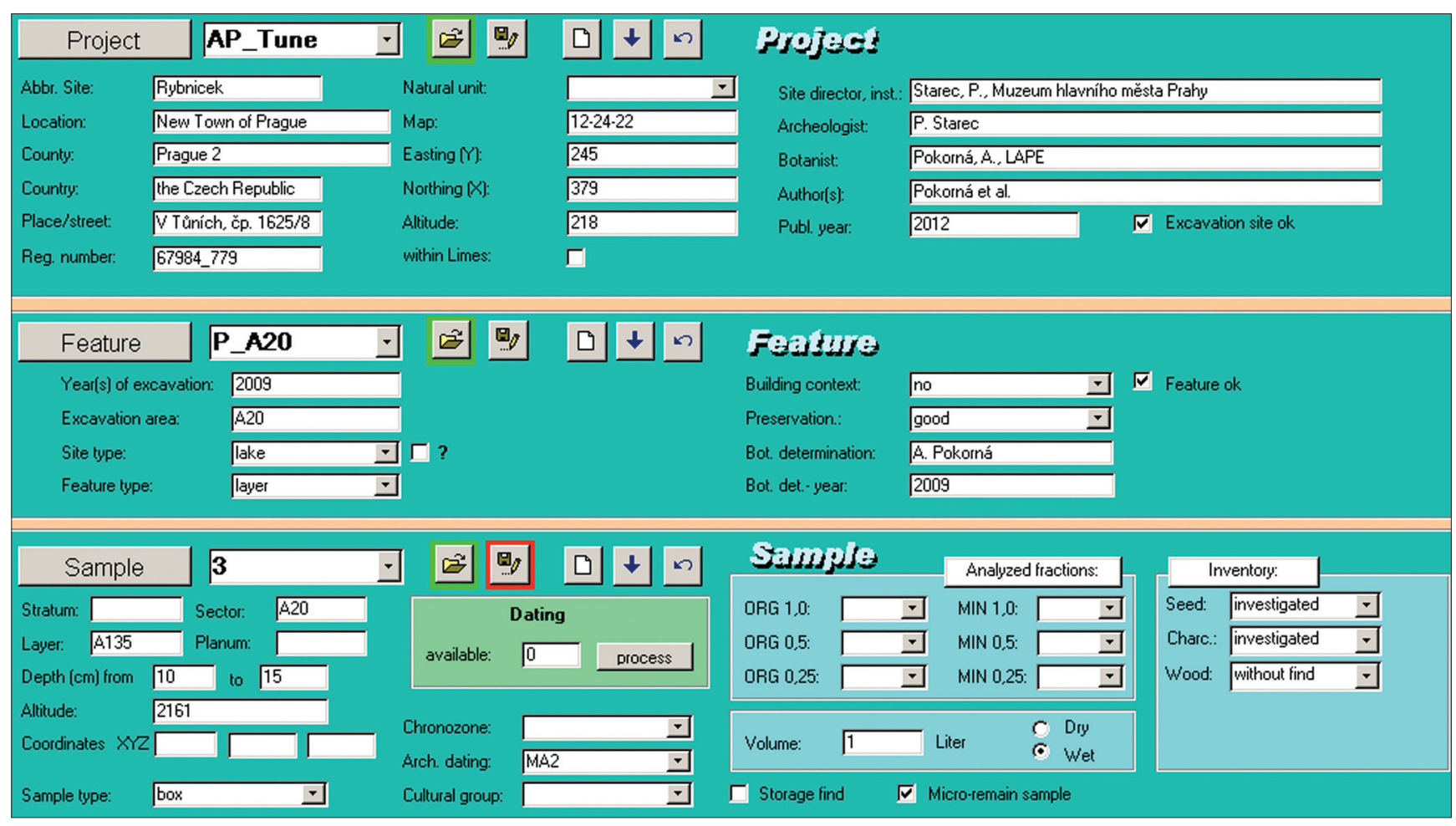

Figure 1. Hierarchical organization of the ArboDat database (Kreuz, Schäfer 2002): Form view of the input mask.

Table 1. Quantitative overview of the archaeobotanical data inserted into the database up to the end of 2010 - according to archaeological periods. Only selected cultures are mentioned.

\begin{tabular}{|c|c|c|c|c|}
\hline Period/culture & & Sum of projects & Sum of samples & Macro-remains \\
\hline Mesolithic & & 1 & 17 & 82 \\
\hline \multirow[t]{4}{*}{ Neolithic } & & 16 & 115 & 3,356 \\
\hline & Linear Pottery Culture & 4 & 36 & 1,106 \\
\hline & Stroked Pottery Culture & 4 & 10 & 205 \\
\hline & Lengyel Culture & 1 & 52 & 403 \\
\hline \multirow[t]{4}{*}{ Eneolithic } & & 18 & 193 & 2,814 \\
\hline & Corded Ware Culture & 3 & 36 & 143 \\
\hline & Jordanov Culture & 2 & 46 & 436 \\
\hline & Bell Beaker Culture & 2 & 48 & 220 \\
\hline \multirow[t]{5}{*}{ Bronze Age } & & 39 & 957 & 35,917 \\
\hline & Únětice Culture & 3 & 68 & 946 \\
\hline & Knovíz Culture & 5 & 82 & 6,182 \\
\hline & Lusatian Culture & 2 & 35 & 858 \\
\hline & Štítary Culture & 1 & 26 & 5,567 \\
\hline \multirow[t]{3}{*}{ Early Iron Age } & & 15 & 205 & 24,054 \\
\hline & Platěnice Culture & 1 & 23 & 3,180 \\
\hline & Hallstatt period & 14 & 182 & 20,874 \\
\hline La Tène Period & & 10 & 224 & 3,696 \\
\hline Roman Period & & 4 & 66 & 5,542 \\
\hline Migration Period & & 1 & 14 & 293 \\
\hline \multirow[t]{3}{*}{ Medieval Period } & & 121 & 1165 & 635,570 \\
\hline & Early Middle Ages & 26 & 166 & 202,012 \\
\hline & High Middle Ages & 70 & 533 & 330,585 \\
\hline Post-medieval Period & & 25 & 89 & 165,235 \\
\hline
\end{tabular}



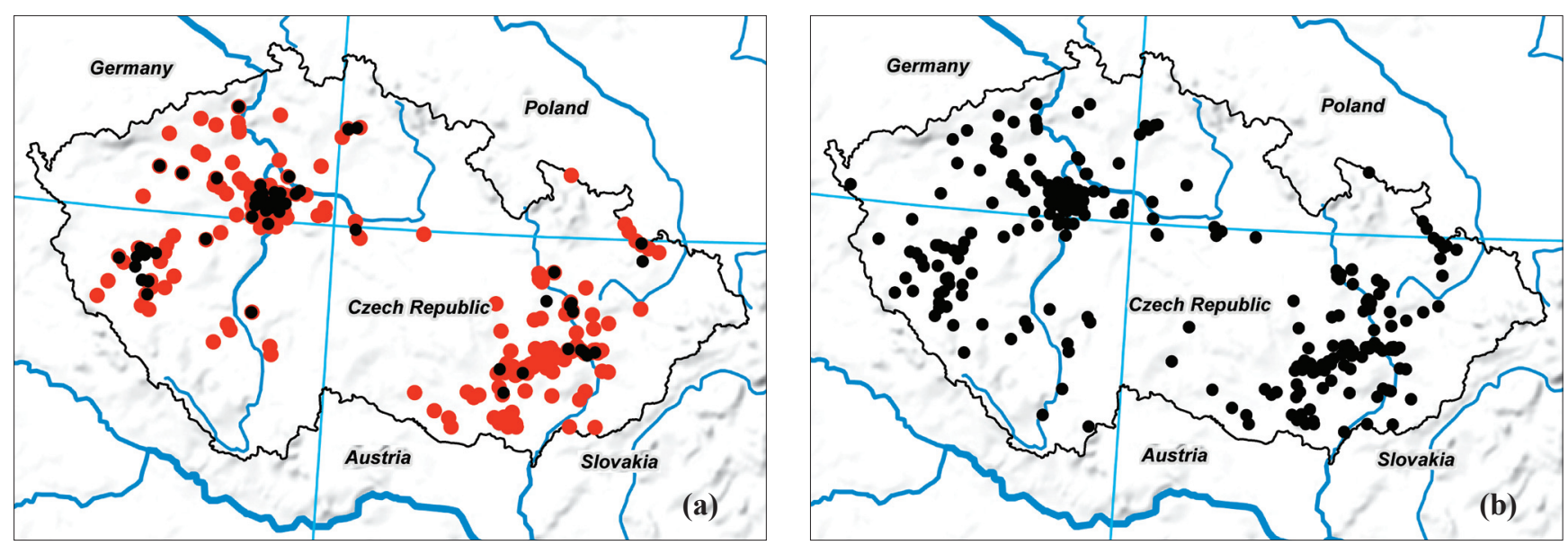

Figure 2. Spatial distribution of archaeological sites with archaeobotanical data within the Czech Republic (status as of end of 2010). (a) Prehistory: black - data already inserted into the database; red - data not yet inserted (according to Kočár, Dreslerová 2010). (b) Early to Post Medieval data inserted into the database.

program is also designed for antracological data and results of wood fragment identification.

Two types of data sources are available - in written and electronic form. Data existing in written form cannot be entered into the database other than manually. However, a special macro is being developed for electronic data to transform MS:Excel tables directly to the MS:Access tables used in ArboDat. Data being currently incorporated into CZAD includes: (a) reports in the ARUP archive; (b) reports provided by individual authors; and (c) published data.

Up to the end of 2010 carpological data from 180 selected archaeological sites had been entered into the database (the only motive for selection was the availability of data). This is roughly more than half of the sites investigated archaeobotanically.

Entered data represent some 3770 processed samples, while the total amount of macro-remains involved exceeds almost one million. For a general overview of the data that has been already incorporated into the database see Table 1. The Medieval Period is represented by the majority of sites (121). In contrast, both the Mesolithic and Roman Period are underrepresented in our data (1 site for each period). The spatial distribution of sites with archaeobotanical finds within the middle European region is shown in Figure 2a) and 2b). A large proportion of the sites are concentrated near cities, a consequence of the increased building activity found there.

It should be noted that all information indicated in both maps on Figure 2 and Table 1 are still interim results; as the input of data to the database is an ongoing process. ${ }^{1}$ This

\footnotetext{
${ }^{1}$ At the time of proofreading of this article the number of archaeological sites inserted to the database increased to 265. The list of the authors of the analyses incorporated by now is as follows: E. Opravil, V. Culíková, Z. Tempír, P. Kočár, V. Komárková, A. Bernardová and A. Pokorná.
}

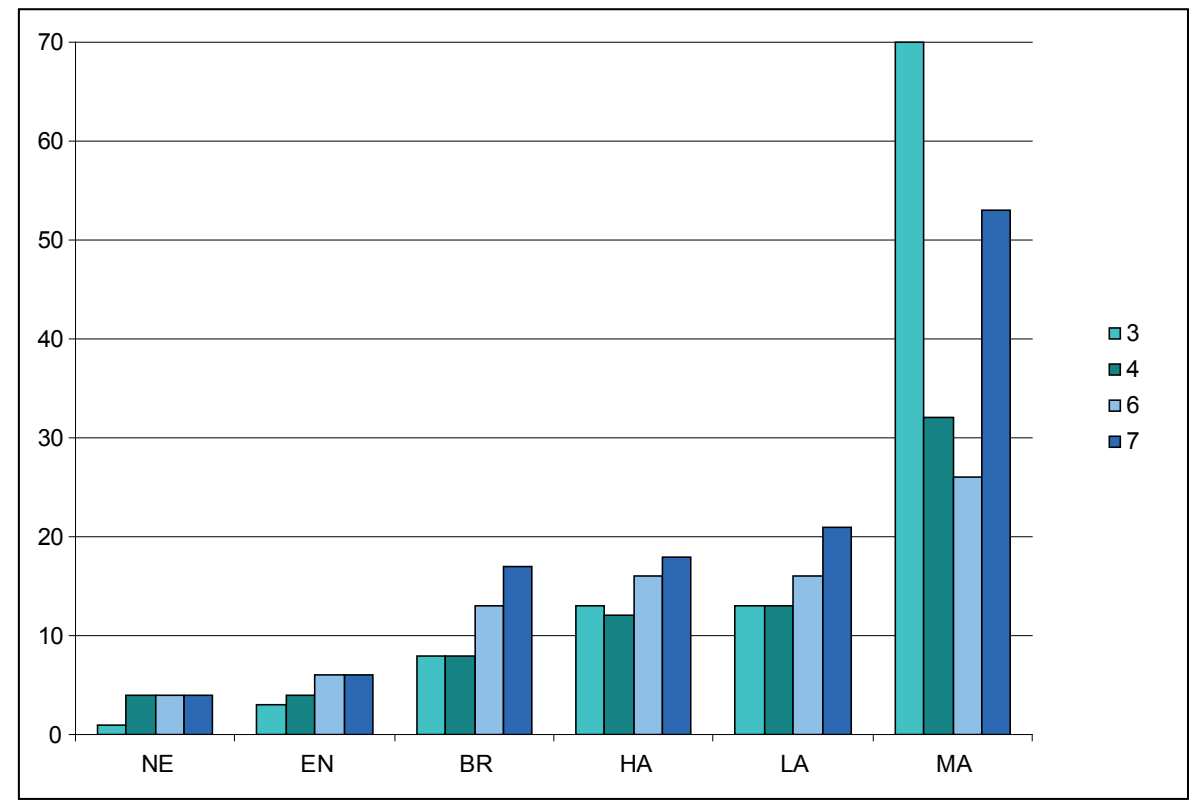

Figure 3. Illustrative example of one use of the archaeobotanical database: weeds and ruderal plants encountered in assemblages of macro-remains in the Czech Republic. Numbers of taxa according to individual archaeological periods (correct up to the end of 2010). Periods: NE - Neolithic, EN Eneolithic, BR - Bronze Age, HA - Hallstatt, LA - La Tène, MA - Medieval. Ecological groups: 3 - ruderal vegetation, 4 - ruderal/ segetal vegetation, 6 - weeds of root-crops and gardens, 7 - weeds of cereals. The classification of taxa follows the individual "ecological" grouping as given by the index in the ArboDat program (Kreuz, Schäfer 2002; Kreuz, Schäfer 2010). 
is the main reason why we have avoided presenting any archaeobotanical data in this text. However, for a small example of the possibilities of the database and the further use of its stored data see Figure 3.

$C Z A D$ was created with the intention of ensuring continuity between earlier analyses, those now in progress, and those done in the future. A centralised database has great advantages for the maintenance and use of all data, particularly in the case of unexpected occurrences (e.g. an author leaves the professional field, an archaeological or archaeobotanical unit ceases to exist, etc.).

Thanks to the current project's funding there is the possibility to enter the bulk of the published data and unpublished reports from individual authors' archives into $C Z A D$ up to the end of 2011. In subsequent years only data that is processed by individual authors in the ArboDat database format will be received and inputed. Updating of the centralised database and merging new data will be performed once a year, in a manner similar to that used by CNRS, France).

The specific rules regarding accessibility, handling and publication of data will be based on the requirements of data contributors. The upgraded version of the merged database will be available to all contributors on CD. ARUP guarantees the protection of authors' copyright and data. The actualised list of localities incorporated into $C Z A D$ will be accessible on the $C Z A D$ web page from the end of 2011 .

\section{Concluding remarks}

Plant macro-remains analysis produces a vast amount of archaeobotanical data, of differing information value in relation to their quantity, site location, time period or excavation and processing methods. A centralized archaeobotanical database may increase the relevance of each of the analyses included: even seemingly marginal or less numerous findings can help to complete a mosaic of discontinuous data and enable a better understanding of the questions asked.

We believe that $C Z A D$ will significantly improve archaeobotanical research in our country. With its help better results may be achieved in a number of research areas, such as the first intentional production of crops, regional and supra- regional agricultural practices, or the migration of plant species, to name but a few. Moreover, a unified database system allows specialists to cooperate at an international level. We hope that the many contributors will participate in its continuing development; despite the fact that the provision and sharing of data is on a strictly voluntary basis, this integrated database is intended for the general benefit of all.

\section{Acknowledgements}

The work on $C Z A D$ was made possible thanks to financial support under a research grant of the Academy of Sciences of the Czech Republic (AS CR) M300020902. We would like to thank Steve Ridgill for improving our English. We would also like to thank Prof. Angela Kreuz for fruitful collaboration.

\section{References}

ČULÍKOVÁ, V. 2004: Archeobotanika v české archeologii na prahu 3. tisíciletí, Archeologické rozhledy 56, 661-671.

DRESLEROVÁ, D. 2008: Better later than never: environmental archaeology in the Czech Republic. In: Beneš, J., Pokorný, P. (Eds.): Bioarchaeology in the Czech Republic. Jihočeská univerzita v Českých Budějovicích, Přírodovědecká fakulta, Archeologický ústav Akademie věd České republiky, Praha, České Budějovice, 13-38.

KOČÁR, P., DRESLEROVÁ, D. 2010:Archeobotanické nálezy pěstovaných rostlin v pravěku České republiky, Památky archeologické 101, 203-242.

KREUZ, A., SCHÄFER, E. 2002: A new archaeobotanical database program, Vegetation History and Archaeobotany 11, 177-179.

KREUZ, A., SCHÄFER, E. 2010:Archäobotanisches Datenbankprogramm ArboDat - Handbuch. Landesamt für Denkmalpflege Hessen, Wiesbaden.

KUNEŠ, P., ABRAHAM, V., KOVAŘÍK, O, KOPECKÝ, M., PALYCZ contributors 2009: Czech Quaternary Palynological Database PALYCZ: Review and basic statistics of the data, Preslia, Praha 81, 209-238.

PAULSEN, J. 1995: Namen und Synonyme mitteleuropäischer Gefässpflanzen. Schweizer Botanik CD 1995, Botanisches Institut der Universität Basel, Basel. 
